\title{
Evaluating Sleeping and Waking States of Infants: Consistency of Actigraph and Observational Data
}

\author{
Rie Nakamura Ikeda1, Kiyoko Fukai² \\ ${ }^{1}$ Department of Nursing, Faculty of Health and Welfare Science, Okayama Prefectural University, Soja, Japan \\ ${ }^{2}$ Graduate School of Health Sciences, Okayama University, Okayama, Japan \\ Email: r-ikeda@fhw.oka-pu.ac.jp
}

Received 18 December 2014; accepted 8 April 2015; published 9 April 2015

Copyright (C) 2015 by authors and Scientific Research Publishing Inc.

This work is licensed under the Creative Commons Attribution International License (CC BY). http://creativecommons.org/licenses/by/4.0/

(c) (7) Open Access

\begin{abstract}
The objective was to evaluate sleeping and waking states of infants $<6$ months old. The design of study was comparing video-recorded and actigraphic data. Participants were thirteen healthy 3 to 5-month-old infants. At their homes, subjects wore an ankle actigraph for $1 \mathrm{~h}$ and were videotaped simultaneously. We performed per-minute analysis of video data using the method for observing newborns developed by Brazelton. Video and actigraphic data were compared each minute. The total concordance rate was $\mathbf{9 3 . 5 \%}$. Sleep/wake identification by actigraphy and visual observation correspond closely for infants.
\end{abstract}

Keywords

Actigraph, Infant, Sleep-Wakefulness, Observation

\section{Introduction}

Infants who are still immature in sleeping and wakefulness patterns run a risk of succumbing to apnea and sudden infant death syndrome (SIDS) during sleep (McIntosh, 2009; McKenna, 2007; Ball, 2006; McKenna, 2005; Gay, 2004). For healthy infants being raised in the home, the most important way to understand the sleep state is observation by caretakers. Neither nurses nor specialized monitoring equipment are available in the home to ascertain sleep state. The sleeping-wakefulness cycle of a baby is closely related to physical and mental fatigue in the mother (Doering, 2013; Lee, 2007; Dennis, 2005; Hiscock, 2004). If a mother can accurately understand the sleep patterns of their baby, this will help them organize time for rest and activities that need to be done. This would then be associated with reductions in maternal mental and physical fatigue.

If the accuracy of visual observation is high, mothers can have confidence in their own observations. For this 
reason, we decided to investigate the degree of consistency between visual observation of sleep state and objective evaluation using specialized equipment. The most reliable method of assessing sleep state would seem to be polysomnography, but this was considered too invasive for application to healthy infants, so actigraphy was used instead.

The actigraph (Micro-mini RC; Ambulatory Monitoring, Ardsley, NY) is a simple, small, non-invasive device that detects and records pressure changes of $\geq 0.01 \mathrm{G}$. Actigraphic data, such as amount of activity, duration of sleep, and frequency of wakefulness, could show problems in infant transition to sleep and development of sleep patterns. The validity of actigraphy for adults (Morgenthaler, 2007; Rajna, 2009; Chokroverty, 2009; Stanley, 2003) and infants (So, 2005) has been accepted.

The aim of this study was to clarify correlations between actigraphy and visual observation in determining sleeping-wakefulness states in Japanese infants.

\section{Methods}

\subsection{Subjects Selecting}

Subjects comprised 13 healthy neonates (age range, 3 - 5 months; mean height, $63.4 \pm 2.8 \mathrm{~cm}$; mean weight, $6872.1 \pm 1041.3 \mathrm{~g})$.

\subsection{Instruments}

In their home, each neonate wore an actigraph on the ankle for $1 \mathrm{~h}$ and was videotaped simultaneously. The actigraph weighed $10 \mathrm{~g}$, was sensitive to $0.01 \mathrm{G}$, sampled at a rate of $16 \mathrm{~Hz}$, and had a nonvolatile memory of 32 $\mathrm{kB}$. Before placing the actigraph, the time on the actigraph was synchronized to the time on the video trace.

\subsection{Analytical Methods}

We analyzed actigraphic data using AW2 software (Gram Corporation, Japan) for automatically identifying sleep/wake states, and the discriminant analysis reported by Sadeh (1989). While we adopt the discriminant analysis described by Cole (1992) in adult subjects, we used Sadeh’s discriminant analysis in neonates to identify the light sleeping state characteristic of this age. Results were categorized into one of three states: sleeping; light sleeping; or wakefulness. We performed a per-minute analysis of video data using the method for observing neonates developed by Brazelton (1961), which was designed to designate the state of a child as one of six categories: State 1, deep sleep; State 2, light sleep; State 3, drowsy; State 4, quiet but alert; State 5, active andalert; and State 6, crying. For comparison with actigraphic data, we defined State 1 as sleeping, State 2 as light sleeping, and States $3-6$ as wakefulness. Both video-recorded data and actigraphic data were reduced to ternary form (1 = sleep; 2 = light sleep; 3 = wakefulness).

Data were analyzed with cross-tabulation using SPSS version 15.0 software (IBM, Chicago, IL), and the agreement rate, predictive value of sleep, predictive value of wakefulness, and Spearman's rank correlation coefficient for actigraphic data and video-analysis were calculated.

\subsection{Ethical Considerations}

We provided an explanation of the purposes and methods of the study and obtained informed consent from mothers at a child-rearing seminar. In addition, we informed the mothers that no disadvantages would be incurred even if they declined to participate. The present study was conducted with the approval of the ethics committees of both Kawasaki University of Medical Welfare (No. 020) and the Graduate School of Health Sciences at Okayama University (No. D05-005).

\section{Results}

In total, 1186 min of video and actigraphic data were compared. A total of 78 min of sleeping state was identified by actigraphy, of which a period of 27 min was determined as the light sleeping state in video analysis. While actigraphy detected 50 min of light sleeping, 18 min of this was identified as sleeping state and 15 min as wakefulness in video analysis. Wakefulness was seen for $1058 \mathrm{~min}$ on actigraphic analysis, of which a period of $13 \mathrm{~min}$ was determined as sleeping state and 4 min as light sleeping in video analysis. The total concordance rate was 93.5\% (Table 1). Spearman's rank coefficient between actigraphic data and video-analysis was $0.865(p=0)$. 
Table 1. Comparison between actigraphic data and video-recorded observation.

\begin{tabular}{ccccc}
\hline $\begin{array}{c}\text { Sleep-awake stages: } \\
\text { Actigraphic prediction } \\
\text { (epoch) }\end{array}$ & \multicolumn{5}{c}{ Sleep-awake stages discriminated by video-recorded data $(\mathrm{n}=13)$} \\
\cline { 2 - 6 } & $\begin{array}{c}\text { Sleep } \\
(82)\end{array}$ & $\begin{array}{c}\text { Light sleep } \\
(48)\end{array}$ & Wakefulness & Total \\
Sleep & 51 & 72 & 0 & 78 \\
Light sleep & 18 & 17 & $156)$ & 50 \\
Wakefulness & 13 & 4 & 1041 & 1058 \\
Total & 82 & 93 & 1056 & 1186 \\
\hline
\end{tabular}

Each number indicates total epochs of data for 13 babies. Predictive value for sleep $=100 * 51 / 78=65.4 \%$; Predictive value for light sleep $=100 *$ $17 / 50=34 \%$; Predictive value for wakefulness $=100 * 1041 / 1058=98.4 \%$; Sensitivity of actigraphy to sleep $=100 * 51 / 82=62.2 \%$; Sensitivity of actigraphy to light sleep $=100 * 17 / 93=18.3 \%$; Sensitivity of actigraphy to wakefulness $=100 * 1041 / 1056=98.6 \%$; Agreement rate $=100 *(51+$ $17+1041) / 1186=93.5 \%$.

\section{Discussion}

The determination of sleeping-wakefulness states by actigraphy corresponded closely with results from video observation of neonates. These findings resembled results of a study that compared actigraphy with polysomnography among infants under 6 months old and found a high (>90\%) rate of agreement (Sadeh, 1989). Mothers sometimes worry that something is wrong when their child does not sleep much, but midwives asked for advice often find nothing wrong, and it seems that mothers may experience difficulty in appropriately interpreting the sleeping states of their babies. This may be partly because the mother is holding or feeding the baby while they are sleeping, so the mother herself is unable to sleep. Keeping a sleeping diary for the baby for a couple of days may reassure the mother and help her to gain a more objective understanding of the baby's sleeping state. By becoming conscious of their baby's sleeping patterns, mothers may also find it easier to sleep. Through confirming concordance between data obtained through observation and actigraphy on sleeping and waking states, this study provides valid evidence that it is possible to understand a baby's sleeping states through observation. Stremler et al. reported that an intervention using a booklet in an approximately 45-min discussion with nurses on sleep for primiparous women and their infants in the early postpartum period had a positive effect on maternal sleep (Stremler, 2013). Methods of guiding mothers to a healthier state through their baby's and their own sleep are currently being explored. Attaching an actigraph to the baby as an intervention to learn about sleeping states is one possible method, but keeping a sleep diary is both simpler and cheaper. Establishing a sleep diary and health guidance using the diary seems to be a good intervention for facilitating better sleep for both babies and their mothers. Although the concordance rate in the light sleeping category was relatively lower than those for sleeping and wakefulness, the overall concordance rate of 93.5\% demonstrated the clinical significance of actigraphy in newborns. Data for this study were collected at home during the daytime, in order to minimize the burden placed on newborns and mothers, so the data on sleeping state used for analysis were limited. We aim to accumulate data on night-time sleeping in the future.

\section{Conclusion}

This study showed high concordance between determinations of sleeping-wakefulness by actigraphy and observation. This can provide reassurance to mothers regarding the importance of visual observation. Furthermore, evidence is shown that sleep-wakefulness state can be determined visually.

\section{Acknowledgements}

This study was supported by a Grant-in-Aid for Scientific Research (No. 16791366).

Partial results from this study were presented at the International Confederation of Midwives 28th Triennial Congress.

\section{References}

Ball, H. L., Ward-Platt, M. P., Heslop, E., Leech, S. J., \& Brown, K. A. (2006). Randomised Trial of Infant Sleep Location 
on the Postnatal Ward. Archives of Disease in Childhood, 91, 1005-1010. http://dx.doi.org/10.1136/adc.2006.099416

Brazelton, T. B. (1961). Psychophysiologic Reactions in the Neonate: I. The Value of Observation of the Neonate. Journal of Pediatrics, 58, 508-512. http://dx.doi.org/10.1016/S0022-3476(61)80184-4

Chokroverty, S. (2009). Sleep and Neurodegenerative Diseases. Seminars in Neurology, 29, 446-467. http://dx.doi.org/10.1055/s-0029-1237124

Cole, R. J., Kripke, D. F., Gruen, W., Mullaney, D. J., \& Gillin, J. C. (1992). Automatic Sleep/Wake Identification from Wrist Activity. Sleep, 15, 461-469.

Dennis, C. L., \& Ross, L. (2005). Relationships among Infant Sleep Patterns, Maternal Fatigue, and Development of Depressive Symptomatology. Birth, 32, 187-193. http://dx.doi.org/10.1111/j.0730-7659.2005.00368.x

Doering, J. (2013). Theoretical Contributions to a Program of Research Promoting Postpartum Health. Applied Nursing Research, 26, 96-98. http://dx.doi.org/10.1016/j.apnr.2012.11.003

Gay, C. L., Lee, K. A., \& Lee, S. Y. (2004). Sleep Patterns and Fatigue in New Mothers and Fathers. Biological Research for Nursing, 5, 311-318. http://dx.doi.org/10.1177/1099800403262142

Hiscock, H., \& Jordan, B. (2004). Problem Crying in Infancy. Medical Journal of Australia, 181, 507-512.

Lee, S. Y., \& Lee, K. A. (2007). Early Postpartum Sleep and Fatigue for Mothers after Cesarean Delivery Compared with Vaginal Delivery: An Exploratory Study. The Journal of Perinatal \& Neonatal Nursing, 21, 109-113. http://dx.doi.org/10.1097/01.JPN.0000270627.73993.b0

McIntosh, C. G., Tonkin, S. L., \& Gunn, A. J. (2009). What Is the Mechanism of Sudden Infant Deaths Associated with Co-Sleeping? New Zealand Medical Journal, 122, 69-75.

McKenna, J. J., \& McDade, T. (2005). Why Babies Should Never Sleep Alone: A Review of the Co-Sleeping Controversy in Relation to SIDS, Bedsharing and Breast Feeding. Paediatric Respiratory Reviews, 6, 134-152. http://dx.doi.org/10.1016/j.prrv.2005.03.006

McKenna, J. J., Ball, H. L., \& Gettler, L. T. (2007). Mother-Infant Cosleeping, Breastfeeding and Sudden Infant Death Syndrome: What Biological Anthropology Has Discovered about Normal Infant Sleep and Pediatric Sleep Medicine. American Journal of Physical Anthropology, 45, 133-161. http://dx.doi.org/10.1002/ajpa.20736

Morgenthaler, T. I., Lee-Chiong, T., Alessi, C., Friedman, L., Aurora, R. N., Boehlecke, B. et al. (2007). Practice Parameters for the Clinical Evaluation and Treatment of Circadian Rhythm Sleep Disorders. An American Academy of Sleep Medicine Report. Sleep, 30, 1445-1459.

Rajna, P., \& Szomszéd, A. (2009). Actigraphy: A Valuable Diagnostic Tool or a Luxury Investigation? (Neuropsychiatric Aspects). Ideggyogyaszati Szemle, 62, 308-316.

Sadeh, A., Alster, J., Urbach, D., \& Lavie, P. (1989). Actigraphy Based Automatic Bedtime Sleep-Wake Scoring: Validity and Clinical Applications. Journal of Ambulatory Monitoring, 2, 209-216.

So, K., Buckley, P., Adamson, T. M., \& Horne, R. S. (2005). Actigraphy Correctly Predicts Sleep Behavior in Infants Who Are Younger Than Six Months, When Compared with Polysomnography. Pediatric Research, 58, 761-765. http://dx.doi.org/10.1203/01.PDR.0000180568.97221.56

Stanley, N. (2003). Actigraphy in Human Psychopharmacology: A Review. Human Psychopharmacology: Clinical and Experimental, 18, 39-49. http://dx.doi.org/10.1002/hup.471

Stremler, R., Hodnett, E., Kenton, L., Lee, K., Weiss, S., Weston, J., \& Willan, A. (2013). Effect of Behavioural-Educational Intervention on Sleep for Primiparous Women and Their Infants in Early Postpartum: Multisite Randomised Controlled Trial. British Medical Journal, 346, f1164. http://dx.doi.org/10.1136/bmj.f1164 